Gut, 1981, 22, 628-632

\title{
Splenic atrophy in adult coeliac disease: is it reversible?
}

\author{
P N TREWBY, P M CHIPPING, S J PALMER, P D ROBERTS, S M LEWIS, AND \\ J S STEWART
}

From the Departments of Gastroenterology and Haematology, West Middlesex Hospital, and Department of Haematology, The Royal Postgraduate Medical School, London

SUMMARY A study of splenic function in 28 patients with adult coeliac disease showed no significant correlation between the half life of heat-damaged red cells and either the duration of pre-treatment exposure to gluten or the length of time on a gluten free diet. A significant correlation was found between splenic size and duration of treatment; those patients who had been taking a gluten free diet for the longest time had the smallest spleens. Blood films from 11 of these 28 patients taken before treatment with a gluten free diet were compared with those taken between two and 15 years after the start of treatment. There was no tendency for the hyposplenic changes to regress. In the majority, the changes became more prominent despite strict adherence to the gluten free diet. These findings suggest that splenic atrophy in adult coeliac disease is not reversed by treatment with a gluten free diet and is unlikely to be related to the state of the jejunal mucosa or the duration of initial exposure to gluten.

Splenic atrophy is now widely recognised as an accompaniment of adult coeliac disease. It has been demonstrated using quantitative techniques such as measuring the half life of heat-damaged red cells and splenic size as defined by area of radioactivity on a rectilinear scan. ${ }^{1-4}$ The recognition of the changes in red cell morphology characteristic of hyposplenism may first alert the physician to the possibility that the patient has adult coeliac disease. ${ }^{5-6}$

The mechanism of splenic atrophy is not known. In inflammatory bowel disease, where splenic atrophy may also occur, improvement in splenic function may follow excision of the diseased bowel. ${ }^{7}$ However, in coeliac disease the small intestinal lesion is presumed to develop in early childhood after weaning onto gluten containing foods. Even if the hyposplenism were related to the mucosal lesion, the factors determining hyposplenism could have been operating long enough to produce irreversible changes by the time a gluten free diet is started in adult life.

In this study we have examined the serial changes in red cell morphology which occur when patients with adult coeliac disease are treated with a gluten free diet. In patients already taking a gluten free diet we have examined the relations between quantitative tests of splenic function and the duration of exposure to gluten before treatment as well as the duration of treatment with a gluten free diet.

\section{Methods}

PATIENTS

Twenty-eight patients were studied. All had been diagnosed as having adult coeliac disease between two months and 23 years previously on the basis of a typical coeliac lesion on intestinal biopsy. Twenty-six patients were followed up for more than one year after the start of treatment and repeat jejunal biopsies were available in 24 . In all but one there was evidence of morphological improvement after treatment with a gluten free diet. In the one patient without morphological improvement serum and red cell folate levels and faecal fat excretion had returned to normal after treatment. The patient subsequently developed a carcinoma of the bronchus and a third jejunal biopsy was not thought to be justifiable. The two patients in whom post-treatment jejunal biopsies were not available had both presented with weight loss, steatorrhoea, and low serum and red cell folate levels. In both, the symptoms resolved and the biochemical and haematological changes returned to 
normal after treatment with a gluten free diet without folate supplements.

Of the 28 patients, 11 were male and 17 female and their mean age at the time of study was 61 years with a range of 16-81 years. They were all being followed up regularly by the same clinician and a dietician with special training and experience in coeliac disease. Only those who were judged to be eating a strict gluten free diet were included in the study. All patients had normal serum and red cell folate levels in the absence of folate supplements.

Routine blood films were examined from each patient for evidence of hyposplenism. Films were examined by one haematologist without knowledge of the patient's clinical details and the appearances were classified as follows: 0: no hyposplenic changes. 1: presence of irregular cells, target cells and spherocytes. 2: grade 1 changes plus Howell-Jolly bodies.

In 11 of these patients blood films were also available from the time of initial diagnosis, which varied from two to 15 years from the time of the present study. These films were coded and examined blind to provide a paired comparison of the effects of a gluten free diet on red cell morphology. In four patients blood films were available from 14 years before the present study but at a time when the patient had been on treatment with a gluten free diet for between two and nine years. The blood films from these patients were also examined and in these, as well as in the remaining patients, the hyposplenic changes were studied in relation to the length of initial exposure to gluten, the number of years' treatment with a gluten free diet, and the age of the patient.

The half life of damaged red cells was assessed by the method described by Bowring, Glass, and Lewis. ${ }^{8}$ Autologous red cells were damaged by heating for 20 minutes at $49 \cdot 5^{\circ} \mathrm{C}$. The cells were labelled with ${ }^{99} \mathrm{Tc}^{\mathrm{m}}$ after pre-tinning with stannous chloride ${ }^{9}$ and the washed cells were reinjected into the patient. Serial blood sampling allowed the rate of clearance of damaged red cells to be determined and scintillation scanning of the abdomen permitted the spleen to be visualised and its area measured by planimetry. In previous control studies we have found the normal range of heat-damaged red cell half lives to be between eight and 16 minutes and the lower limit of splenic area to be $45 \mathrm{~cm}^{2}$. In the 28 patients the relations between these quantitative tests of splenic function and both the length of initial gluten exposure and the duration of treatment with a gluten free diet were determined.

Statistical analyses were performed using Spearman's rank correlation coefficient and the MannWhitney U Test.

The study was approved by the local ethical committee and each patient gave informed consent. Patients were not selected on account of pre-existing hyposplenism; the tests of hyposplenism were carried out only after the patient had agreed to participate in the study.

\section{Results}

When changes in red cell morphology indicative of hyposplenism were examined there was little to suggest any regression after treatment with a gluten free diet. In five of the 11 patients in whom paired films were available before and after starting treatment the hyposplenic changes became more prominent with treatment. In only one patient was treatment associated with a regression of the hyposplenic changes (Fig. 1). In all four patients in whom paired films were available after starting treatment the hyposplenic changes progressed with time and Howell-Jolly bodies were found in one patient after 17 years' treatment (Fig. 1).

Taking the patients as a whole, it was found that those who had hyposplenic changes in their peripheral blood film were those who had been on treatment for the longest period of time. The mean duration of treatment in those with hyposplenic changes in the peripheral blood film was $8 \cdot 7 \pm 1$ SD $6 \cdot 2$ years and in those without $3 \cdot 9 \pm 1$ SD $5 \cdot 3$ years $(\mathrm{P}<0 \cdot 01$, Table).

No relation was found between the number of years the patient had been taking gluten before diagnosis and the severity of the hyposplenic changes in the peripheral blood film, the mean length of gluten exposure in those with and without hyposplenic changes being $50 \cdot 1 \pm 1$ SD $16 \cdot 1$ and $54 \cdot 1 \pm 1$ SD 16. 1 years respectively.

Analysis of the quantitative tests of splenic function showed eight of the 28 patients to have prolonged red cell half lives and 12 of the 28 small spleens. Seven patients had both small spleens and prolonged red cell half lives and all but one of these had red cell morphological changes of hyposplenism.

An inverse correlation was found between splenic area and the length of time on treatment (Fig. 2),

Table Relations between red cell morphological changes, length of treatment with a gluten free diet, and duration of initial exposure to gluten

\begin{tabular}{llll}
\hline $\begin{array}{l}\text { Red cell } \\
\text { changes }\end{array}$ & $\begin{array}{l}\text { Years on } \\
\text { treatment }\end{array}$ & $\begin{array}{l}\text { Years exposed } \\
\text { to gluten }\end{array}$ & $\begin{array}{l}\text { Age } \\
\text { (years) }\end{array}$ \\
\hline $0(10)$ & $3 \cdot 9 \pm 5 \cdot 3$ & $54 \cdot 1 \pm 16 \cdot 1$ & $57 \cdot 8 \pm 11 \cdot 1$ \\
$1(8)$ & $8 \cdot 6 \pm 12 \cdot 4$ & $46 \cdot 6 \pm 11 \cdot 0$ & $55 \cdot 0 \pm 14 \cdot 1$ \\
$2(10)$ & $8 \cdot 8 \pm 13 \cdot 3$ & $56 \cdot 7 \pm 16 \cdot 8$ & $63 \cdot 8 \pm 12 \cdot 3$ \\
\hline
\end{tabular}

Values refer to means \pm 1 SD.

Numbers in parentheses refer to numbers of patients. 


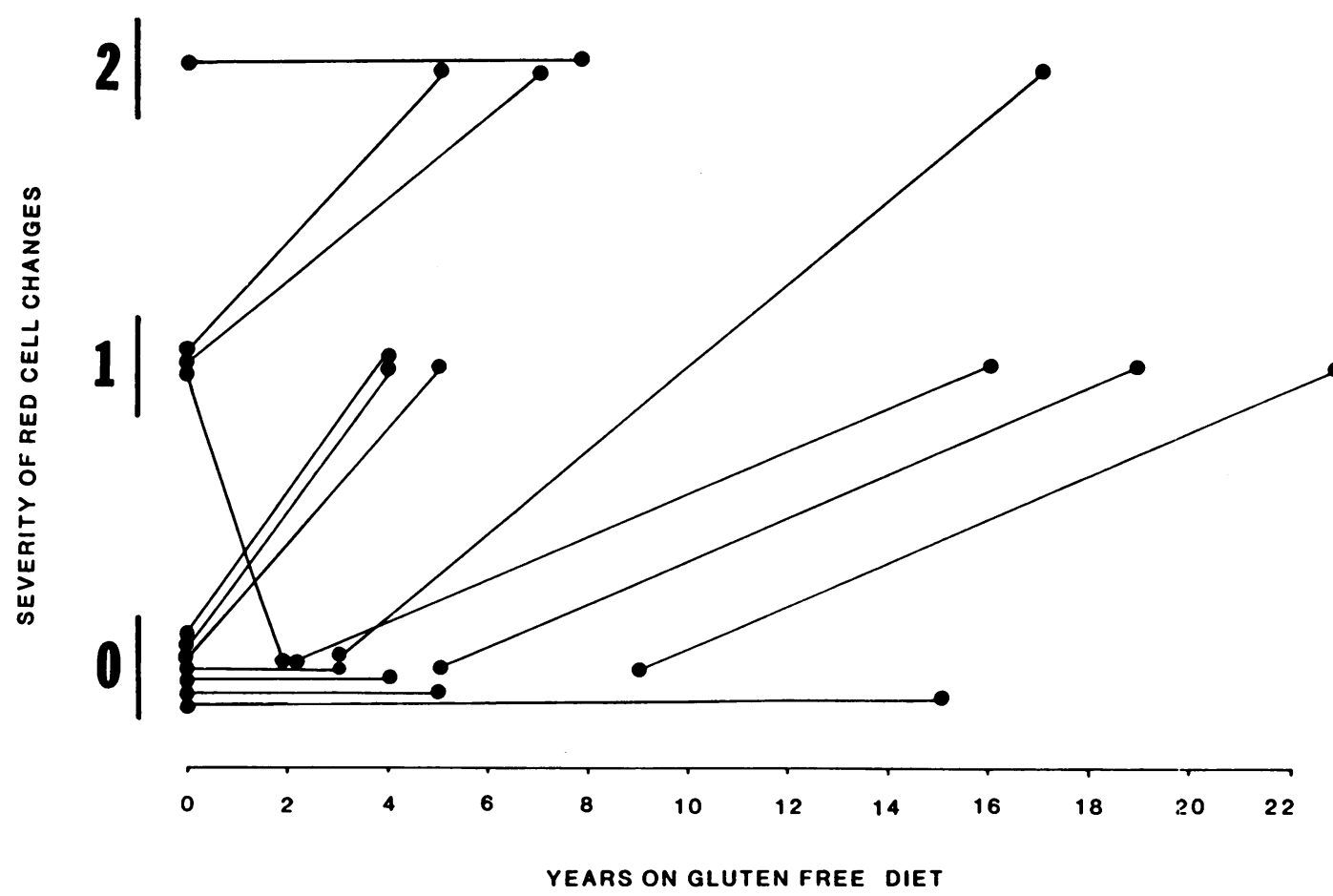

Fig. 1 Serial studies of red cell hyposplenic changes in patients with adult coeliac disease while receiving a gluten free diet. 0: no hyposplenic changes. 1: presence of irregular cells, target cells, and spherocytes. 2: Grade I changes plus Howell-Jolly bodies.

those patients with the smallest splenic areas having been on treatment for the longest period of time and vice versa. A statistically significant inverse correlation was also found between splenic area and the age of the patient at the time of study $(r=-0 \cdot 46, \mathrm{P}<0 \cdot 02)$. No correlation was found between splenic area and the duration of gluten exposure before diagnosis $(r=0 \cdot 17)$. Nor was any significant correlation found between the half life of damaged red cells and the age of the patient $(r=0.32)$, the length of initial gluten exposure $(r=0 \cdot 27)$, or the number of years treated with a gluten free diet $(r=0.095)$.

Analysis of the relation between the different tests of splenic function showed a significant correlation between splenic area and the half life of heatdamaged red cells $(r=-0.48, \mathrm{P}<0.02)$. In addition, those patients with Howell-Jolly bodies in the peripheral blood film had significantly smaller splenic areas than those without (mean values $36 \cdot 0 \pm 1$ SD $12.4 \mathrm{~cm}^{2}$ and $52 \cdot 4 \pm 12 \cdot 3 \mathrm{~cm}^{2}$ respectively, $\left.\mathrm{P}<0 \cdot 001\right)$. However, there was no difference in red cell half lives between the two groups (mean values $20 \cdot 1 \pm 1$ SD $14 \cdot 4$ in those with and $13.9 \pm 2.6$ minutes in those without HowellJolly bodies).

No abnormality was seen on histological examina- tion of the jejunal biopsy from one patient taken soon after her splenic studies. This patient was selected for a third jejunal biopsy because she had the most Howell-Jolly bodies in the peripheral blood film and the second longest red cell half life of the present series (31 minutes).

\section{Discussion}

The results in these 28 patients with adult coeliac disease suggest that withdrawal of gluten from the diet was not associated with any regression of the associated hyposplenic changes. Indeed, duration of treatment was associated with a deterioration in two of the three tests of hyposplenism used in this study. These findings are in keeping with necropsy studies in adult coeliac disease ${ }^{10}$ which have shown the spleen to be thickly encapsulated with fibrous tissue and the red pulp to be replaced by bands of fibrous tissue, changes which would not be expected to be readily reversible with treatment. However, the few previous reports of splenic function measured serially in patients with adult coeliac disease have shown conflicting results. Although Palmer et al. ${ }^{11}$ showed a reduction in splenic area in some patients after treat- 
Fig. 2 Relation between splenic size $\left(\mathrm{cm}^{2}\right)$ and length of treatment with a gluten free diet in 28 patients with adult coeliac disease $(r=-0.46, \mathrm{P}<0.02)$.

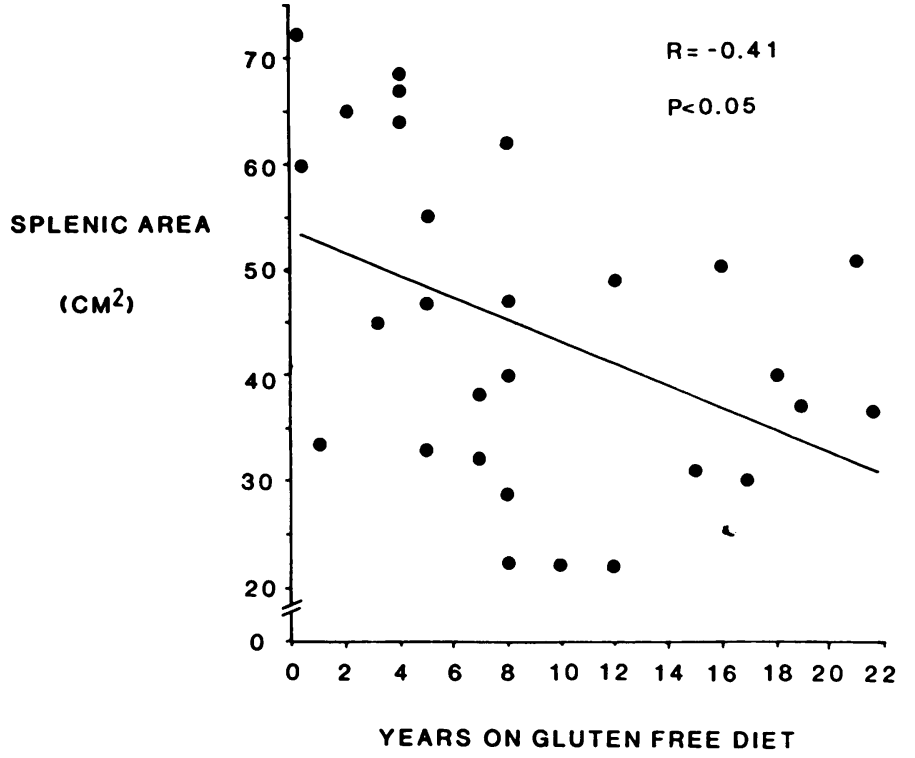

ponent representing splenic activity. However, in common with other authors, ${ }^{1711}$ we accepted the more readily available blood clearance of damaged red cells as a suitable test of splenic function.

Studies of red cell half life were available in five of our patients from 14 years before the present study. These earlier studies were performed using ${ }^{51} \mathrm{Cr}$ and were not repeated using the same isotope because the method exposes the patient to more radiation than the present technique. Comparison of the two values in each of the five patients showed no significant change in red cell half life over the 14 year period, although the two methods may not be strictly comparable. Without serial studies of red cell half life using the same isotope, we cannot exclude the possibility that in some patients treatment with a gluten free diet was associated with a return of splenic function towards normal. However, the progressive reduction in splenic area and the persistence of hyposplenic changes in the peripheral blood film suggest that a major element of hyposplenism remained despite treatment with a gluten free diet.

It is unlikely that continued exposure to gluten was the cause of the persistent hyposplenism. Careful repeated dietary review by the same dietician revealed no evidence of gluten ingestion and values for red cell and serum folate were normal in all patients. Furthermore, jejunal histology was normal in the patient with the most Howell-Jolly bodies in the peripheral blood film. The reduction in splenic size with treatment may be a non-specific ageing effect, for splenic size and function are known to decrease 
with age ${ }^{2}$ and in our patients there was a significant inverse correlation between the age of the patient and the splenic area. This is also in keeping with previous studies which have shown blood film changes of hyposplenism to be rare in young patients with coeliac disease. $^{4}$

In dermatitis herpetiformis where splenic atrophy also occurs Pettit et al. ${ }^{17}$ found no relation between the associated abnormality of jejunal morphology and the degree of hyposplenism. Our results suggest a similar dissociation in adult coeliac disease. It may be that the tendency to hyposplenism and the associated lymphoreticular atrophy which occur in adult coeliac disease $^{4}$ are genetically determined, being related to the presumed genetic determinants of adult coeliac disease but unaffected by treatment of the disease with a gluten free diet.

A practical consideration is that the presence of hyposplenic changes in the peripheral blood film cannot be used as evidence of poor dietary compliance. Howell-Jolly bodies may occur in patients who keep strictly to a gluten free diet and who have normal red cell and serum folate levels as well as normal jejunal morphology.

We thank Dr V S Chadwick for his cooperation in allowing us to restudy five of his patients. We are also grateful to Dr A Knudsen, Department of Histopathology, West Middlesex Hospital, for the histology of the intestinal biopsies and to our dietician, Mrs Maureen MacDonald, for her painstaking work.

\section{References}

'Marsh GW, Stewart JS. Splenic function in adult coeliac disease. Br J Haematol 1970; 19: 445-57.

${ }^{2}$ Pettit JE. Spleen function. Clin Haematol 1977; 6: 639-56.
${ }^{3}$ Bullen AW, Hall R, Gowland G, Losowsky MS. Relationship of hyposplenism, adult coeliac disease and autoimmunity. Gut 1978; 19A: 438.

${ }^{4}$ McCarthy CF, Fraser ID, Evans KT, Read AE. Lymphoreticular dysfunction in idiopathic steatorrhoea. Gut 1966; 7: 140-8.

${ }^{5}$ Stewart JS. Adult coeliac disease. Postgrad Med J 1968; 44: 632-40.

${ }^{6}$ Ferguson A, Hutton M, Maxwell BD, Murray D. Adult coeliac disease in hyposplenic patients. Lancet 1970; 1: 163-4.

${ }^{7}$ Ryan FP, Smart RC, Holdsworth CD, Preston FE. Hyposplenism in inflammatory bowel disease. Gut 1978; 19: 50-5.

${ }^{8}$ Bowring CS, Glass HI, Lewis SM. Rate of clearance by the spleen of heat-damaged erythrocytes. J Clin Pathol 1976; 29: 852-4.

'Jones J, Mollison PL. A simple and efficient method of labelling red cells with ${ }^{99} \mathrm{M}$ Tc for determination of red cell volumes. Br J Haematol 1978; 38: 141-8.

${ }^{10}$ Ferguson A. Coeliac disease and gastrointestinal food allergy. In: Ferguson A, MacSween RNM, eds. Immunological aspects of the liver and gastrointestinal tract, Lancaster: MTP Press, 1976: 173.

"Palmer KR, Sherriff SB, Holdsworth CD. Changing pattern of splenic function in coeliac disease (Abstract). Gut 1979; 20A: 920.

${ }^{12}$ Nelson EW, Estan A, Brooks FP, Cerda JJ. Thrombocytosis in patients with coeliac sprue. Gastroenterology 1976; 70: 1042-4.

${ }^{13}$ Bullen AW, Hall R, Brown RC, Losowsky MS. Mechanisms of thrombocytosis in coeliac disease. Gut 1977; 18A: 962.

${ }^{14}$ Szur L, Marsh GW, Pettit JE. Studies of splenic function by means of radioisotope-labelled red cells. Br J Haematol 1972; 23: suppl 183-9.

${ }^{15}$ Bullen AW, Losowsky MS. Consequences of impaired splenic function. Clin Sci 1979; 57: 129-37.

${ }^{16}$ Smart RC, Ryan FP, Holdsworth CD, Preston FE. Relationship between splenic size and splenic function. Gut 1978; 19: 56-9.

${ }^{17}$ Pettit JE, Hoffbrand AV, Seah PP, Fry L. Splenic atrophy in dermatitis herpetiformis. Br Med J 1972; 2: 438-40. 